their platelet count and clinical manifestations of thrombocytopenia: the aim should be to wean them from this form of treatment as soon as possible and so avoid prolonged immunosuppression in patients who have become stabilised and might well manage better without it.

${ }^{1}$ Doan CA, Bouroncle BA, Wiseman BK. Idiopathic and secondary thrombocytopenic purpura. Clinical study and evaluation of 381 cases over a period of 28 years. Ann Intern Med 1960;53:861-76.

${ }^{2}$ Picozzi VJ, Roeske WR, Creger WP. Fate of therapy failures in adult idiopathic thrombocytopenic purpura. Am $\mathcal{F}$ Med 1980;69:690-4.

3 Aster RH, Keene WR. Sites of platelet destruction in idiopathic thrombocytopenic purpura. Br f Haematol 1969 ;16:61-73.

${ }^{4}$ Ries CA, Price DC. ${ }^{51} \mathrm{Cr}$ platelet kinetics in thrombocytopenia. Correlation between splenic sequestration of platelets and response to splenectomy. Ann Intern Med $1974 ; 80: 702-7$

5 Najean Y, Ardaillou N. The sequestration site of platelets in idiopathic thrombocytopenic purpura: its correlation with the results of splenectomy. Br $\mathcal{F}$ Haematol 1971 ;21:153-64.

6 Scheffel U, Tsan M-F, McIntyre PA. Labelling of human platelets with ${ }^{111}$ In 8-hydroxyquinoline. 7 Nucl Med 1979;20:524-31.

7 Heyns A du P, Lötter MG, Bradenhorst PN, et al. Kinetics, distribution and sites of destruction of ${ }^{111}$ indium-labelled human platelets. $\mathrm{Br} \mathcal{F}$ Haematol $1980 ; 44: 269-80$.

${ }^{8}$ Klonizakis I, Peters AM, Fitzpatrick ML, Kensett MJ, Lewis SM, Lavender JP. Radionuclide distribution following injection of ${ }^{111}$ indiumlabelled platelets. Brf Haematol $1980 ; 46$ :595-602

${ }^{9}$ Peters AM, Klonizakis I, Lavender JP, Lewis SM. Use of ${ }^{11}$ indiumlabelled platelets to measure spleen function. Br $\mathcal{F}$ Haematol 1980;46 587-93.

10 Finch SC, Castro O, Cooper M, Covey W, Erichson R, McPhedran P. Immunosuppressive therapy of chronic idiopathic thrombocytopenic purpura. Am ₹ Med $1974 ; 56: 4-12$.

11 Ahn YS, Harrington WJ, Seelman RC, Eytel CS. Vincristine therapy of idiopathic and secondary thrombocytopenias. N Engl F Med 1974;291: 376-80.

12 Ahn YS, Byrnes JJ, Harrington WJ, et al. The treatment of idiopathic thrombocytopenia with vinblastine-loaded platelets. $N$ Engl $\mathcal{f}$ Med $1978 ; 298: 1101-7$

\section{Postoperative radiotherapy in breast cancer}

Recently almost every aspect of the treatment of breast cancer has come under the spotlight of critical review; and the wide interest in the topic is shown by the correspondence (25 April, $p$ 1392) stimulated by our leader on breast conservation (7 March, $p$ 759). One of the most vexed questions is the value of postoperative radiotherapy with cancerous axillary lymph nodes. ${ }^{1}$ Postoperative radiotherapy is time consuming, costly, and not without morbidity; so how good is the case for its routine use after radical surgery in patients with spread to the axillary nodes? The issue is now further complicated by the possible risks of using radiotherapy in conjunction with adjuvant chemotherapy. At present treatment programmes vary from centre to centre, with clinical trials still in progress.

Spread to the axillary lymph nodes certainly carries a bad prognosis-the more nodes affected the worse the outlookbut there is a group of long-term survivors who have diseased nodes at the time of their primary treatment. ${ }^{2}$ The available evidence shows that with modern techniques and equipment radiotherapy can sterilise the area of the breast and regional nodes in about $90 \%$ of cases without much morbidity. The long-term effects are less certain. Opinion is divided on whether patients with diseased nodes can be cured by radical local treatments or can at least achieve a normal life expectancy. The treatment hawks believe that breast cancer behaves like most other cancers and goes through a longer or shorter stage when it has spread to the regional nodes but has not disseminated. They will practise radical local and regional treatments, usually including postoperative radiotherapy, and will probably also use adjuvant chemotherapy and hormones prophylactically to take care of disseminated disease. The disadvantages of radiotherapy and the risks of associating it 3 with chemotherapy are written off against the chance of $a \stackrel{\infty}{\circ}$ "cure."

The treatment doves believe that the presence of spread to the axillary lymph nodes signifies advanced and disseminated disease, and their therapeutic efforts are directed to establishing local control to prevent the disappointment and misery of m local recurrences and to treating disseminated disease symptomatically with chemotherapy or hormones or both.

Clinical trials of postoperative radiotherapy have given $\frac{9}{0}$ conflicting results, and their design has been criticised. ${ }^{3}$ The $\frac{\bar{\sigma}}{\sigma}$ Manchester $^{4}$ and the Cancer Research Campaign ${ }^{5}$ trials $^{3}$ showed no benefit in terms of survival at 10 years for the stage $\stackrel{\Phi}{\circ}$ I or stage II patients having radiotherapy routinely postoperatively. They did, however, record an unacceptably high $\vec{P}$ rate (about $45 \%$ ) of local and regional recurrence in patients with stage II disease. Høst and Brennhovd ${ }^{6}$ achieved a small $\vec{\omega}$ improvement in survival in patients with diseased nodes at five $\frac{\stackrel{\rho}{\circ}}{2}$ years using cobalt irradiation.

Opinion seems likely to remain divided on the place of $\underset{\infty}{\sim}$ postoperative radiotherapy. Though there is little evidence to ? support radical radiotherapy except to prevent local recur- N rences, some clinicians will continue to use it after radical or 0 conservative surgery and will cover the breast or pectoral scar $\overrightarrow{\vec{t}}$ and the axillary, supraclavicular, and internal mammary $\infty$ nodes. ${ }^{7}$ Others will use radiotherapy only in selected cases 9 with the aim of preventing local recurrence or will withhold 6 routine postoperative treatment and use it only if and when local recurrence develops.

The place of adjuvant chemotherapy has yet to be $\stackrel{\otimes}{\otimes}$ established in the long term. Originally this treatment was. intended to eradicate micrometastases after local radical treatment, and increasingly intensive courses are now being recommended on the basis of Bonadonna's studies. ${ }^{8}$ Whether these intensive courses will control "bulk" local and regional $\frac{0}{D}$ disease remains to be seen. If local control can be established $\stackrel{2}{\not}$ and maintained by adjuvant chemotherapy postoperative $\stackrel{?}{?}$ radiotherapy will no longer be needed, so eliminating the potential risks of combining radiotherapy and chemotherapy.

The main questions being asked by clinicians now-and being put to trial-are not so much which operation, or how much radiotherapy, but which combination of treatment modalities is optimum. A question mark remains over the 3 long-term safety of radiotherapy, though earlier fears that it $\dot{\delta}$ reduced patients' resistance to the development of metastases $₹$ has not been confirmed. ${ }^{910}$ The Breast Cancer Trials Co- 9 ordinating Subcommittee in Britain is organising a meeting $N$ this year to pool and analyse the long-term results of clinical trials which have included radiotherapy as one treatment $\stackrel{\text { ? }}{\text {. }}$. option, in the hope of shedding some light on the long-term $N$ effects of radiotherapy as well as establishing more clearly the N value of postoperative irradiation.

Until chemotherapy has proved itself in the treatment of regional disease and until (or indeed if) radiotherapy can be $\underset{\Phi}{\Phi}$

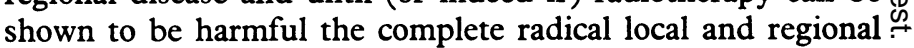
treatment for patients with breast cancer and affected axillary $\frac{0}{0}$ lymph nodes still requires postoperative radiotherapy. One $\frac{\vec{D}}{\mathrm{D}}$ of the few certainties in breast cancer is that radiotherapy will $\frac{\mathrm{O}}{\mathrm{O}}$ prevent local recurrences if it is used in association with more $\frac{0}{\sigma}$ conservative procedures.

${ }^{1}$ Lipsett MB. Postoperative radiation for women with cancer of the breast and positive axillary lymph nodes. Should it continue ? $N$ Engl $\mathcal{F}$ Med ़ㅡㄱ 1981 ;304:112-4. 
${ }^{2}$ Brinkley D, Haybittle JL. The curability of breast cancer. Lancet 1975; ii :95-7.

${ }^{3}$ Fletcher GH, Montague ED. Does adequate irradiation of the internal mammary chain and supraclavicular nodes improve survival rates? Int 7 Radiat Oncol Biol Phys 1978;4:481-92.

4 Easson EC. Post-operative radiotherapy in breast cancer. In: Forrest APM, Kunkler PB, eds. Prognostic factors in breast cancer. Edinburgh: Livingstone, 1968:118-27.

${ }^{5}$ Cancer Research Campaign Working Party. Cancer Research Campaign (King's/Cambridge) trial for early breast cancer: a detailed update at the tenth year. Lancet 1980 ;ii:55-60.

${ }^{6}$ Høst $\mathrm{H}$, Brennhovd IO. The effect of post-operative radiotherapy in breast cancer. Int $\mathcal{F}$ Radiat Oncol Biol Phys 1977;2:1061-7.

${ }^{7}$ Handley RS. Carcinoma of the breast. Ann R Coll Surg Engl 1975;57: 59-66.

${ }^{8}$ Bonadonna G, Valagussa P. Dose-response effect of adjuvant chemotherapy in breast cancer. N Englf Med $1981 ; 304: 10-5$.

${ }^{9}$ Stjernswärd J. Decreased survival related to irradiation postoperatively in early operable breast cancer. Lancet 1974 ;ii:1285-6.

${ }^{10}$ Levitt $\mathrm{SH}$. The role of radiation therapy in the treatment of breast cancer: the use and abuse of clinical trials, statistics and unproven hypotheses. Int $\mathcal{F}$ Radiat Oncol Biol Phys 1980;6:791-8.

\section{Diagnosis of ascites}

Free fluid in the peritoneal cavity in excess of one litre may be detected by observing abdominal distension, displacement of the umbilicus towards the symphysis pubis, shifting dullness, and a fluid thrill. Volumes as small as $200 \mathrm{ml}$ are detectable with the patient in the knee-elbow position-the puddle sign. ${ }^{1}$ Liver disease remains the most common cause of prominent ascites $^{2}$; malignancy, congestive cardiac failure, tuberculosis, and chronic pancreatitis are other important possibilities. Each condition has confirmatory clinical features, but rarer causes such as renal disease, myxoedema, and constrictive pericarditis should also be considered.

The first choice of diagnostic techniques has swung recently in favour of those that are non-invasive. A plain abdominal radiograph shows generalised loss of density and detail especially of the hepatic angle, and in the supine lateral view the gut may be seen floating on top of the fluid. Ultrasound is more sensitive and can detect as little as $300 \mathrm{ml}^{3}$; it gives a characteristic picture not only of hepatic metastases and abdominal masses but also of malignant ascites, with a pattern of mottled or infiltrated loops of bowel and loculation of fluid. ${ }^{4}$ Such a pattern is not invariably found in malignancy, however, being seen in under two-thirds of one small series, ${ }^{4}$ and absence of these features does not exclude cancer, especially when only a little fluid is present.

A diagnostic tap, using a fine-bore needle, is a more direct approach if the origin of the ascites is still not clear. A lot may be learnt from the naked-eye appearance of the fluid: bloodstaining suggests trauma or carcinoma, chylous fluid is found in lymphatic obstruction, and the diagnosis is confirmed if the chylomicrons separate into the supernatant fluid; turbidity indicates infection; bile staining is associated with trauma, pancreatitis, gall stones, neoplasia, and recent biliary surgery; and clear, straw-coloured fluid occurs in parenchymal liver disease. The concentration of protein may also be a valuable guide, but care must be taken in interpretation of this result: textbooks state that the protein content of ascitic fluid in uncomplicated cirrhosis is below $25-30 \mathrm{~g} / \mathrm{l}$, but several workers have noted values above this in up to $17 \%$ of patients. ${ }^{56}$ Even so, high protein concentrations should raise the suspicion of pancreatic or tuberculous peritonitis, and in the latter case the glucose concentration may also be low, though such a finding is not diagnostic.?
High concentrations of $\alpha$-fetoprotein are found in the serum and the ascitic fluid in patients with hepatomas, but contrary to earlier. suggestions raised gamma-glutamyltransferase activity does not have the same diagnostic value. ${ }^{8} \mathrm{~A}$ serosanguinous fluid with an amylase activity greater than 20000 Somogyi units and raised lipase activity is said to be a reliable indicator of pancreatic ascites. ${ }^{9}$ The serum activity of lactate dehydrogenase is lower than that in the ascitic fluid in malignant ascites and the ratio is reversed in cirrhosis; the accuracy of the test may be improved by also calculating the ratio of serum to ascitic total protein. ${ }^{10}$

Normally, sterile ascites contains fewer than $300 \times 10^{6}$ white blood cells $/ 1\left(300 / \mathrm{mm}^{3}\right)$ with under $25 \%$ polymorphonuclear leucocytes, and spontaneous bacterial peritonitis, occurring in about $10 \%$ of cirrhotics with ascites, ${ }^{11}$ should be suspected when the cell count exceeds $500 \times 10^{6} / 1$ and over half the cells present are polymorphonuclear leucocytes. ${ }^{6}$ Culture and Gram and Ziehl-Nielsen staining should always be performed on a centrifuged sample. When the white cell count is greater than $500 \times 10^{6} / 1$ and mononuclear cells predominate, tuberculosis, malignancy, and pancreatic causes should be borne in mind; high white cell counts have also, however, been noted in cirrhotic patients treated with diuretics. ${ }^{12}$ Cytological diagnosis of malignant cells in ascitic fluid is extremely difficult because of the varying morphology and staining characteristics of exfoliated mesothelial cells, ${ }^{13}{ }^{14}$ but methods using marker chromosomes may provide better information.

If the diagnosis remains uncertain more invasive techniques, such as peritoneoscopy or laparotomy, may have to be used to obtain evidence of metastases, ovarian cysts, or portal hypertension. Percutaneous peritoneal biopsy is a less invasive technique which has been used successfully to diagnose tuberculous peritonitis, ${ }^{15}$ but its success rate in confirming carcinomatous ascites is less impressive.

${ }^{1}$ Lawson JD, Weissbein AS. The puddle sign-an aid in the diagnosis of minimal ascites. $N$ Engl f Med 1959;260:652-4.

2 Berner C, Fred HL, Riggs S, Davis JS. Diagnostic probabilities in patients with conspicuous ascites. Arch Intern Med 1964;113:687-90.

${ }^{3}$ Goldberg BB, Clearfield HR, Goodman GA, Morales JO. Ultrasonic determination of ascites. Arch Intern Med 1973;131:217-20.

4 Edell SL, Gefter WB. Ultrasonic differentiation of types of ascitic fluid. $A 7 R$ 1979;133:111-4.

${ }^{5}$ Sampliner RE, Iber FL. High protein ascites in patients with uncomplicated hepatic cirrhosis. Am $\mathcal{F}$ Med Sci 1974 ;267:275-9.

${ }^{6}$ Boyer TD, Kahn AM, Reynolds TB. Diagnostic value of ascitic fluid lactic dehydrogenase, protein and WBC levels. Arch Intern Med 1978;138:1103-5.

${ }^{7}$ Brown JD, Nguyen DAC An. Tuberculosis peritonitis. Low ascitic fluid glucose concentration as a diagnostic aid. Am $\mathcal{F}$ Gastroenterol $1976 ; 66: 277-82$.

${ }^{8}$ Olsson $R$, Waldenström J. Gamma-glutamyltransferase activity in ascitic fluid in diagnosis of hepatocellular carcinoma. $\mathrm{Br}$ Med 7 1979; ii :830-1.

9 Sileo AV, Chawla SK, LoPresti PA. Pancreatic ascites: diagnostic importance of ascitic lipase. Am F Dig Dis 1975;20:1110-4.

${ }^{10}$ Greene LS, Levine R, Gross MJ, Gordon S. Distinguishing between malignant and cirrhotic ascites by computerized step-wise discriminant functional analysis of its biochemistry. Am $\mathcal{f}$ Gastroenterol 1978;70: 448-54.

${ }^{11}$ Kline MM, McCallum RW, Guth PH. The clinical value of ascitic fluid culture and leukocyte count studies in alcoholic cirrhosis. Gastroenterology 1976;70:408-12.

12 Stanley MM, McKeever JW, Bedford DE. Ascitic fluid (AF) cell counts in "uncomplicated" cirrhotics: evidence that cell concentrations increase during diuresis. Gastroenterology $1974 ; 66: \mathrm{A} 128 / 782$.

13 Grunze $\mathrm{H}$. The comparative diagnostic accuracy, efficiency and specificity of cytologic technics used in the diagnosis of malignant neoplasm in serous effusions of the pleural and pericardial cavities. Acta Cytol (Baltimore) $1964 ; 8: 150-63$.

${ }^{14}$ McGuckin WF, Soule EH, Cain JC, Bartholomew LG, Rovelstad RA. The value of glycoprotein determination and cytology in the study of ascitic fluid. Gastroenterology 1959;37:332-8.

${ }^{15}$ Jenkins PF, Ward MJ. The role of peritoneal biopsy in the diagnosis of ascites. Postgrad Med $\mathcal{F} 1980 ; 56: 702-3$. 